\title{
Biochemical Markers of Excitability in Human Neocortex
}

\author{
A.L. Sherwin, O. Vernet, F. Dubeau and A. Olivier
}

\begin{abstract}
We measured biochemical markers of excitability in brain excised for neurosurgical therapy of epilepsy. Intraoperative electrocorticography was used to identify and compare samples from regions of persistent interictal spike discharges and areas of the cerebral convexity which were free of interictal spiking. We found that interictal spiking was associated with elevated tissue levels of the excitatory amino acids glutamic acid $(26 \%, \mathrm{p}<0.001)$ and aspartic acid $(25 \%, \mathrm{p}<0.05)$. There was also a significant increase in the activity of the enzymes glutamic acid dehydrogenase $(20 \%, \mathrm{p}<0.01)$ and aspartate acid aminotransferase $(18 \%, \mathrm{p}<0.01)$ which are involved in their formation. There was no change in the levels of the inhibitory neurotransmitters GABA or taurine. We also found a significant increase in the activity of tyrosine hydroxylase $(52 \%, \mathrm{p}<0.001)$, the rate controlling enzyme in catecholamine biosynthesis. There was a reduction in the density (Bmax) of cortical alpha- 1 adrenoceptors $(26 \%, p<0.01)$ and a concommitant diminution of receptor coupled phosphatidylinositide metabolism $(21 \%, \mathrm{p}<0.01)$. This blunting of inhibitory noradrenergic transmembrane signaling may contribute to a relative imbalance between excitatory and inhibitory mechanisms in epileptogenic neocortex.
\end{abstract}

RÉSUMÉ: Marqueurs biochimiques de l'excitabilité dans le néocortex humain. Certains marqueurs biochimiques de l'excitabilité ont été mesurés dans du tissu cérébral humain obtenu lors de la chirurgie de l'épilepsie. Un électrocorticogramme per-opératoire a permis d'identifier puis de comparer des échantillons de néocortex provenant d'une part de régions produisant continuellement des pointes en période inter-critique et d'autre part de zones totalement dépourvues de ce type d'anomalie électrique. La présence de pointes a pu être associée à une élévation des taux tissulaires des acides aminés excitateurs glutamate $(26 \%, \mathrm{p}<0.001)$ et aspartate $(25 \%, \mathrm{p}<0.05)$ ainsi que de l'activité des enzymes responsables de leur formation: la glutamate deshydrogénase $(20 \%, \mathrm{p}<0.01)$ et l'aspartate aminotransférase $(18 \%, \mathrm{p}<0.01)$. Par contre, aucune altération des taux des neurotransmetteurs inhibiteurs GABA et taurine n'a été objectivée. Nous avons égalément démontré une augmentation significative de l'activité de la tyrosine hydroxylase $(52 \%, p<0.001)$, l'enzyme modulant la biosynthèse des catécholamines. La présence de pointes a été de surcroît corrélée avec une diminution de la densité (Bmax) des récepteurs alpha-1-adrénergiques corticaux $(26 \%, \mathrm{p}<0.01)$, ainsi que de l'hydrolyse du phosphatidylinositol (PI) qui leur est associée $(21 \%, \mathrm{p}<0.01)$. Cette diminution du signal transmembranaire inhibiteur noradrénergique pourrait contribuer à un déséquilibre relatif entre les influences excitatrices et inhibitrices dans le néocortex épileptique.

Can.J. Neurol. Sci. 1991; 18: 640-644

Location-related epilepsies have numerous etiologies but have in common a period of maturation, during which aberrant local neuronal networks are created and eventually develop a capacity for spontaneous synchronous discharges..$^{1-3}$ Human tissue analysis is essential in this disorder because the prolonged latent period cannot be fully reproduced during the short lifespan of laboratory animals. ${ }^{4}$ Epileptogenic lesions are subtle and require precise EEG localization; before operation all patients undergo extensive EEG-video seizure monitoring with various types of extracranial and in some cases intracranial electrodes. 5,6 Antiepileptic drugs are partially or completely withdrawn to enhance the localization of epileptic activity. Sites of focal spiking as well as surrounding nonspiking regions are identified by means of electrocorticography (ECoG) with surface electrodes at operation under local anesthesia.7,8 Temporary depth electrodes are employed during surgery to detect epileptic activity in the hippocampus and amygdala. On the basis of the ECoG findings, we classify neocortical specimens into the following groups: (A) Spontaneous interictal spiking restricted to either the anterior or posterior portions of one of the first two temporal gyri. In this paradigm, a nonspiking control sample is obtained from the quiescent half of the same gyrus. ${ }^{9}$ (B) Widespread spontaneous interictal spiking recorded from the lateral surface of the temporal lobe. In this model, nonspiking control samples are obtained from patients in whom the epileptogenic lesion was confirmed to the hippocampus and/or amygdala sparing the cerebral convexity. ${ }^{10}$ (C) Neocortical specimens obtained from patients with no history of seizures are also used as controls.

From the Montreal Neurological Institute and the Department of Neurology and Neurosurgery, McGill University, Montreal

Reprint requests to: Allan L. Sherwin, M.D., Montreal Neurological Institute, 3801 University Street, Montreal, Quebec, Canada H3A 2B4 
These histologically normal tissues were excised during the course of deep seated tumor removal. After excision of samples for biochemical analysis, immediately adjacent regions of cortex and white matter are fixed or otherwise prepared for histopathology and immunochemistry. ${ }^{11}$ The extent of neuronal loss and astrocytosis are appraised separately and graded as described by Robitaille. ${ }^{4}$ Spiking and nonspiking areas sampled for biochemical determinations are always located outside regions of gross atrophy or other structural abnormalities.

Measurements of receptors, neurotransmitters, and regulatory enzymes in brain excised for surgical therapy of epilepsy have identified a number of biochemical markers of neocortical excitability. $12-14$ These metabolic abnormalities have been delineated further by examining signal transduction mechanisms and intracellular messengers in freshly prepared in vitro human neocortical slices. ${ }^{15}$ The electrographic hallmark of an epileptic focus is the ictal, or seizure, discharge accompanied by the patient's habitual attack. The interictal spike discharge remains however the earliest and simplest indicator of a region with a high epileptogenic potential. ${ }^{1}$ In appraising biochemical data derived from analysis of epileptogenic brain it is important to take into consideration whether the tissue sample was obtained: (a) during or following a seizure discharge accompanied by behavioral attack (ictal); (b) from a site of persistent interictal spike discharges (spiking); (c) or from a region of neocortex with a quiescent background activity (nonspiking).

\section{Excitatory Amino Acids as Markers}

The excitatory amino acid neurotransmitters (EAA) glutamic and aspartic acid have consistently been implicated in the pathophysiology of both experimental and human 16,17 focal epilepsy. These observations have been highlighted by evidence that some EAA antagonists are potent anticonvulsants. ${ }^{16} \mathrm{We}$ found a significant increase in the levels of glutamic acid $(+26 \%, \mathrm{p}<$ $0.001)$ and aspartic acid $((+25 \%, \mathrm{p}<0.05)$ in actively spiking lateral temporal neocortex. ${ }^{10}$ There was also an increase in the concentration of glycine $(+55 \%, \mathrm{p}<0.001)$ confirming the earlier findings of van Gelder et al. ${ }^{18}$ Glycine greatly potentiates physiological responses mediated by the NMDA-sensitive subclass of synaptic receptors. ${ }^{19}$ Increased glycine in spiking neocortex may reflect a seizure-induced increase in pyruvate and lactate levels. 12 There was no diminution in the tissue concentrations of the inhibitory neurotransmitters GABA and taurine in the epileptogenic zones which is in keeping with earlier reports. ${ }^{18,19}$ Interestingly, the amino acid concentration profile of quiescent or nonspiking neocortex from patients with epilepsy was within the range reported for samples of neocortex obtained from nonepileptic subjects. ${ }^{20}$ Our findings point to a relative imbalance between putative excitatory and inhibitory amino acid levels in spiking neocortex. ${ }^{17}$ Studies of amino acid release and turnover are required to determine the functional significance of these changes. Recently, increased glutamate, and taurine levels in extracellular fluid in patients with hippocampal seizures were measured by means of microdialysis probes combined with stereotaxically implanted electrodes. ${ }^{21}$ Interictal spike activity correlated with dialysate lactic acid concentration which is a biochemical marker of increased glucose utilization.

\section{Amino Acid Enzymes Regulating Metabolism as Markers}

Chronically epileptogenic human brain appears to have a greater capacity for the rapid formation of excitatory amino acids than the naive neocortex of animal models. This notion is supported by an examination of enzymes that regulate glutamic and aspartic acid metabolism (Figure 1). We found a modest but significant increase $(+20.4 \%, \mathrm{p}<0.001)$ in the activity of glutamic acid dehydrogenase (GDH) in interictal spike foci versus nonspiking control neocortex. 22 This enzyme plays an important role in the formation of glutamic acid by the reductive amination of alpha-ketoglutarate derived from the tricarboxylic acid cycle. As GDH is localized to astrocytes, this reaction also serves to detoxify free ammonia which is a byproduct of epileptic activity. In collaboration with Dr. S. Kish, ${ }^{23}$ we also examined the behavior of aspartic acid aminotransferase (AAT), an astroglial enzyme involved in both aspartic and glutamic acid metabolism. This enzyme catalyses the reversible reaction converting aspartic acid to glutamic acid and oxaloacetate to alpha ketoglutarate. AAT activity was significantly increased $(+18 \%$, $\mathrm{p}<0.01$ ) in spiking vs. nonspiking neocortex. A similar association between interictal epileptic discharges and the activity of enzymes involved in acetylcholine metabolism has been reported. ${ }^{24}$ A neurotoxic side effect of EAA excess would be neuronal loss as well as astrogliosis in both the gray matter and immediately subcortical white matter. Interestingly, there was a statistically significant correlation ( $p<0.02, N=16$ patients) between the activity of AAT measured in the direction of aspartic acid formation and the graded histopathological severity of reactive astrocytosis. 23 The abundance of mature metabolically-activated astrocytes likely contributes to enhanced EAA turnover in epileptogenic zones. In human neocortex, mature astrocytes with increased GDH and AAT activity are likely able to transiently increased glutamic and aspartic acid levels when stimulated by interictal spiking. There is a basal release of glutamic acid from brain surface which is augmented by interictal discharges. $14,21,25$ However, chronic epileptogenic cortex has a capacity to store and maintain higher total tissue glutamate concentrations, likely because of the relative increase in the size of the glial compartment. 14.17 This may not be the case, however, if ictal epileptic foci could be examined. In this situation, it is most likely that the tissue levels of glutamic and aspartic acid would be diminished in keeping with the findings in cobaltinduced seizure foci in cats. 25,26

\section{Noradrenergic Markers}

The central noradrenergic system is another source of biochemical markers of excitability because it modulates synaptic activity by altering postsynaptic responsiveness to other neurotransmitters including GABA. Iontophoretic studies indicate that norepinephrine (NE) plays a mainly inhibitory role in the neocortex. ${ }^{27}$ Noradrenergic fibers arising in the locus coeruleus are widely distributed throughout the neocortex in a laminar fashion. ${ }^{28}$ Cortical noradrenergic afferents play a definitive role in the pathogenesis of several animal models of epilepsy. ${ }^{13,29}$ We found that the activity of tyrosine hydroxylase (TH), which is the rate-limiting enzyme in catecholamine synthesis, was significantly increased (mean $+52 \%$ ) in spiking versus nonspiking epileptogenic cortex (Table 1). The activity of the various $\mathrm{TH}$ enzymes reflect neocortical discharge rates; depolarizing stimuli including raised extracellular $\left(\mathrm{K}^{+}\right)$levels enhance total $\mathrm{TH}$ activity. ${ }^{30}$

Though alpha- 1 adrenoceptors generally subserve excitatory functions in the CNS, they may mediate inhibitory effects in 

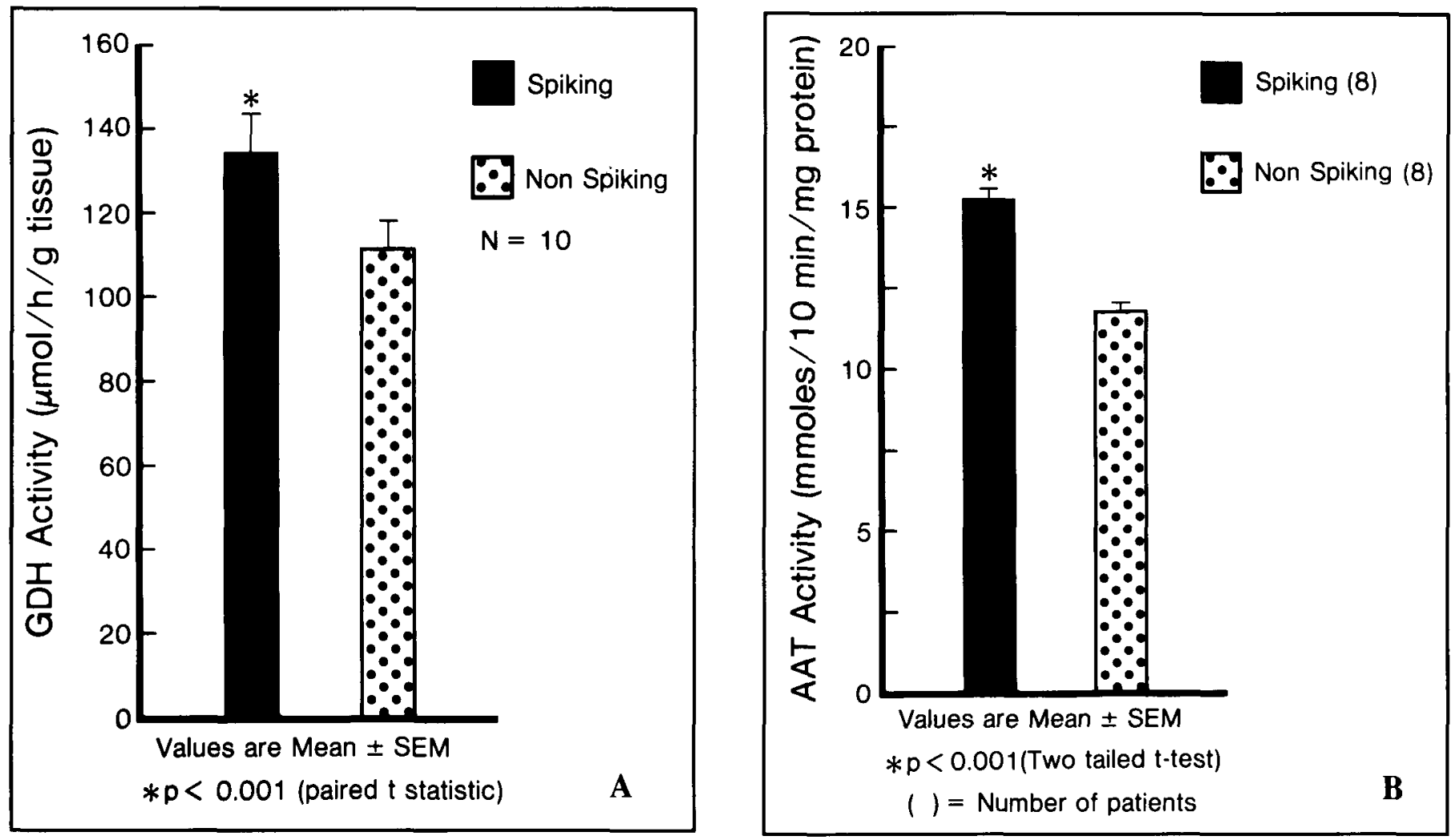

Figure $1 \mathrm{~A})$ - Glutamic acid dehydrogenase $(G D H)$ activities in paired samples of spiking and nonspiking neocortex. Patients studied were those in whom spontaneously active spiking was restricted to either the anterior or posterior portions of one of the first two temporal gyri. Control samples were obtained from the quiescent anterior or posterior half of the same gyrus approximately $4 \mathrm{~cm}$ away. B) Aspartic acid aminotransferase activity in actively spiking lateral temporal neocortex, control nonspiking samples were obtained from a separate group of patients in whom the epileptogenic lesion was confined to the hippocampus andlor amygdala sparing the cerebral convexity.

experimentally-induced cortical spike foci. ${ }^{31}$ In collaboration with Brière and Reader, ${ }^{9}$ we assayed cortical membrane alpha- 1 adrenoceptors by radioligand binding in paired samples of spiking and nonspiking neocortex in eight patients with focal lateral temporal interictal spike discharges. There was a significant reduction in the mean receptor density maximal binding capacity (Bmax) of the alpha- 1 adrenoceptors in membranes prepared from regions where consistent spiking had been demonstrated by ECoG (Table 1). No differences were observed in the apparent dissociation constant $(\mathrm{Kd})$, which is a measure of the affinity of the receptors for the test ligand. A localized decrease in noradrenergic inhibition could contribute to the emergence of pacemaker neurons with intrinsic burst generating capacities which have been postulated to give rise to the characteristic high-frequency synchronous discharges of focal cortical epileptogenesis. ${ }^{1-3}$

\section{Phosphatidylinositol Metabolites as Markers}

Adrenergic mediated phosphatidylinositol (PI) metabolism was measured in vitro in neocortical tissue slices. $15 \mathrm{We}$ observed a significant reduction (mean, $21 \%, \mathrm{p}<0.01 ; \mathrm{N}=25$ patients) in PI metabolism as measured by inositol phosphate (IP-1) accumulation (Table 1). There was a good correlation between the frequency of epileptic spike discharges recorded during intraoperative ECoG and the reduction in the PI response (Figure 2). The relative diminution in maximal epinephrine stimulated IP-1 accumulation (Emax) is to be expected in light of the decrease observed in alpha- 1 adrenoceptor density (Bmax). In neuronal primary cultures, exposure of the cells to norepinephrine for 2 hours or more significantly downregulated the number of alpha- 1 cell surface recognition sites and reduced alpha- 1 receptor stimulated PI metabolism. 32 Brief exposure $(<2$ h) of neuronal primary cultures to NE however, results in a loss of responsiveness without a change in the density (Bmax)

Table 1: Comparison of Biochemical Markers of Catecholamine Metabolismin Epilepsy Surgery Specimens and Nonspiking Human Neocortex

\begin{tabular}{lcc}
\hline \hline & Spiking & Nonspiking \\
\hline Tyrosine hydroxylase activity $^{\mathrm{a}}$ & $18.7 \pm 2.0^{*}(10)$ & $12.3 \pm 2.0(10)$ \\
$\alpha-1$ adrenoceptors density $(\mathrm{Bmax})^{\mathrm{b}}$ & $156.5 \pm 13.1^{*}(8)$ & $227.0 \pm 17.5(8)$ \\
Maximal PI response (\% basal) $^{\mathrm{d}, \mathrm{e}}$ & $526 \pm 19 *(19)$ & $669 \pm 35(9)$ \\
& & $603 \pm 91\left(4^{\mathrm{f}}\right)$ \\
\hline
\end{tabular}

Values are mean $\pm \mathrm{SEM}, * \mathrm{p}<0.01$ (two-tailed t-lest), parenthesis signify number of patients.

$\mathrm{a}-\mathrm{nmol} / \mathrm{h} / \mathrm{wet} \mathrm{wt}$; $\mathrm{b}$ - spiking and nonspiking samples from the same patient; $c$ - fmol/mg protein; $d$ - alpha-1 receptor coupled PI response expressed as a percentage of total $\left({ }^{3} \mathrm{H}\right) \mathrm{IP} 1$ accumulation; $\mathrm{e}$ - spiking and nonspiking samples from two separate groups of patients; $f$ - non epileptic neurosurgical patients 


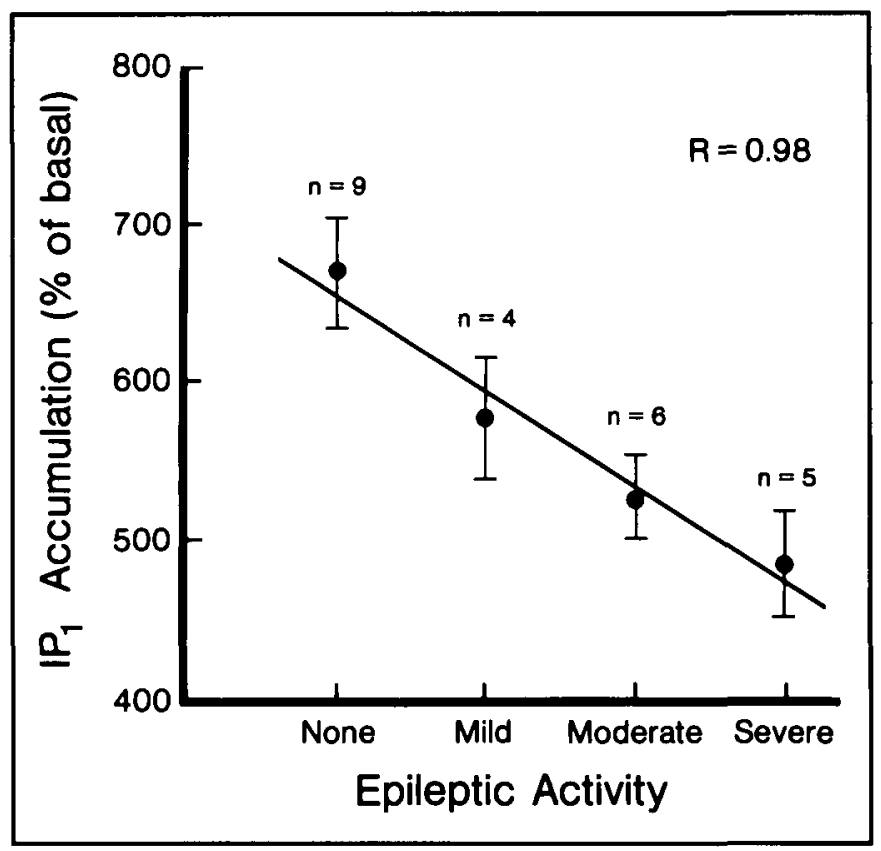

Figure 2 - Effect of the severity of epileptic activity on phosphatidylinositol metabolism. Patients were divided into four groups: None, no epileptic activity; mild, less than 8 spikes a minute; moderate, between 8 to 16 spikes/minute or greater; and severe, between 16 to 32 spikes/minute or greater. This graph is plotted to demonstrate the correlation between the relative frequency of interictal spike discharges as recorded by intraoperative ECoG and the maximal accumulation of inositol monophosphate (IPI) used as an index of adrenergic mediated PI turnover. Data are expressed as a percentage of total $(3 H) I P_{I}$ accumulation in the absence of any agonist. Each point represents the mean $+S E M, n$ signifies the number of patients. (From Sherwin et al. with permission).

of alpha-1 receptor sites (desensitization). Interestingly, this effect is mimicked by exposing the cells to phorbol ester which activates protein kinase $\mathrm{C}$, suggesting that the desensitization mechanism involves phosphorylation of various components of the system..$^{33}$ In rat neocortical slices, NE stimulation of alpha-1 receptor mediated PI hydrolysis is inhibited by pretreatment with glutamic acid. ${ }^{34}$ This finding provides a mechanism whereby the excitatory amino acids released during epileptic discharges could contribute to the desensitization of alpha-1 adrenoceptor mediated responses. We suggest that epileptic activity modulates PI transmembrane signalling either by receptor downregulation or by other mechanisms of desensitization that modify receptor-effector coupling. This reduction of noradrenergic transmission may reflect a localized diminution in various neurotransmitter mediated inhibitory mechanisms in epileptic neocortex.

\section{ACKNOWLEDGEMENT}

This work was supported by the Medical Research Council of Canada. Dr. Vernet was a postdoctoral fellow of the Fonds Decker, CHUV, Lausanne and Janggen-Poehn Stiftung, St. Gall, Switzerland. Dr. Dubeau was a postdoctoral fellow of the Fonds de la Recherche en Santé du Québec. We thank Drs. F. Andermann, F. Quesney, E. Andermann and Y. Robitaille for helpful advice and Ms. B. Whiston for preparing the manuscript.

\section{REFERENCES}

1. Dichter MA, Ayala GF. Cellular mechanisms of epilepsy: A status report. Science 1987; 237: 157-164.

2. Prince A. Physiological mechanisms of focal epileptogenesis. Epilepsia 1985; 26 (Suppl 1): S3-S14.

3. Engel J, Jr. New concepts of the epileptic focus. In: Wieser HG, Speckmann EG, Engel J, Jr, eds. The Epileptic Focus. London: John Libbey Eurotext, 1987.

4. Robitaille Y. Neuropathological findings in epileptic foci. $\ln$ : Wieser HG, Speckmann EG, Engel J, Jr, eds. The Epileptic Focus. London: John Libbey Eurotext 1987; 95-112.

5. Quesney LF, Gloor P. Localization of epileptic foci. In: Gotman J, Ives JR, Gloor P, eds. Long Term Monitoring in Epilepsy. Electroenceph Clin Neurophysiol, Suppl 37. Amsterdam Elsevier 1985; 165-200.

6. Gotman J, Marciani MG. Electroencephalographic spiking activity, drug levels, and seizure occurrence in epileptic patients. Ann Neurol 1985; 17: 597-603.

7. Olivier A. Cortical resections. In: Engel J, Jr, ed. Surgical Treatment of the Epilepsies. New York: Raven Press 1987; 405424.

8. Gloor P. Contributions of electroencephalography and electrocorticography to the neurosurgical treatment of epilepsies. $\ln$ : Purpura DP, Penry JK, Walters RD, eds. Advances In Neurology, vol 8: Neurosurgical Management of the Epilepsies. New York: Raven Press 1975; 59-105.

9. Brière R, Sherwin AL, Robitaille Y, et al. Alpha-1 adrenoceptors are decreased in human epileptic foci. Ann Neurol 1986; 19: 2630.

10. Sherwin AL, Robitaille Y, Quesney F, et al. Excitatory amino acids are elevated in human epileptic cerebral cortex. Neurology 1988; 38: $920-923$.

11. Sherwin AL. Guide to neurochemical analysis of surgical specimens of human brain. Epilepsy Res 1988; 2: 281-288.

12. Chapman AG. Amino acid abnormalities in plasma, CSF and brain in epilepsy. In: Pedley TA, Meldrum BS, eds. Recent Advances in Epilepsy. Vol 4. New York: Churchill Livingston 1988; 46-62.

13. Delgado-Esqueta AV, Ward AA, Jr, Woodbury DM, et al. New wave of research in the epilepsies. In: Delgado-Esqueta AV, Ward AA, Jr, Woodbury DM, Porter RJ, eds. Basic Mechanisms of the Epilepsies. New York: Raven Press 1986; 1011-1032.

14. Sherwin AL, van Gelder NM. Amino acid and catecholamine markers of metabolic abnormalities in human focal epilepsy. In: Delgado-Esqueta AV, Ward AA, Jr, Woodbury DM, Porter RJ, eds. Basic Mechanisms of the Epilepsies. New York: Raven Press 1986; 1011-1032.

15. Dubeau F, Sherwin AL. Adrenergic mediated phosphatidylinositol metabolism is modulated by epileptic discharges in human neocortex. Brain Res 1989; 481: 200-203.

16. Meldrum B. Possible therapeutic applications of antagonists of excitatory amino acid neurotransmitters. Clin Sci 1985; 68: 113 122.

17. Van Gelder NM. Contributions of basic neurochemistry towards a novel concept of epilepsy. Neurochem Res 1987; 12:111-119.

18. Van Gelder, Sherwin AL and Rasmussen T. Amino acid content of epileptogenic human brain: focal versus surrounding regions. Brain Res 1972; 40: 385-393.

19. Johnson JW, Asher P. Glycine potentiates the NMDA response in cultured mouse brain neurons. Nature 1987; 325: 529-531.

20. Perry TL, Hansen S. Amino acid abnormalities in epileptogenic foci. Neurology 1981; 31: 872-876.

21. During MJ, Anderson GM, Roth RH, et al. A human dialytrode: in vivo measurements of neuroactive substances in the human hippocampus with simultaneous depth EEG recordings. Soc Neurosci Abstr 1989; 15: 140.8 .

22. Sherwin AL, Quesney F, Gauthier S, et al. Enzyme changes in actively spiking areas of human epileptic cerebral cortex. Neurology 1984; 34: 927-933.

23. Kish SJ, Dixon LM, Sherwin AL. Aspartic acid aminotransferase activity is increased in actively spiking compared with non-spiking human epileptic cortex. J Neurol Neurosurg Psychiatry 1988; 51: 552-556. 
24. Kish SJ, Olivier A, Dubeau F, et al. Increased activity of choline acetyltransferase (ChAT) and cholinesterase (AchE) activity in spiking vs nonspiking human epileptic cortex. Epilepsy Res 1988; 2: 227-231.

25. Koyama I. Amino acids in the cobalt-induced epileptogenic and nonepileptogenic cat's cortex. Can J Physiol Pharmacol 1972; 50: 740-752.

26. Van Gelder NM, Courtois A. Close correlation between changing content of specific amino acids in epileptogenic cortex of cats and severity of epilepsy. Brain Res 1972; 43: 477-484.

27. Reader TA, Ferron A, Decarries L, et al. Modulatory role for biogenic amines in the cerebral cortex. Brain Res 1979; 160: 217 . 229.

28. Sherwin AL, Dyve S, Dubeau F, et al. Postictal compensatory changes in cortical alpha-1 receptors and adrenergic-mediated phosphoinositol metabolism following repeated electroconvulsive seizures in rats. In: Avoli M, Gloor P, Kostopoulos G, Naquet R, eds. Generalized Epilepsy: Cellular, Molecular, Pharmacological Approaches. Boston: Birkhauser 1990; 407-422.

29. Trottier S, Lindvall O, Chauvel P, et al. Facilitation of focal cobaltinduced epilepsy after lesions of the noradrenergic locus coeruleus system. Brain Res 1988; 454: 308-314.

30. Haycock JW. Stimulation-dependent phosphorylation of tyrosine hydroxylase in rat corpus striatum. Brain Res Bull 1987; 19(6): 619-622.

31. Neuman RS. Suppression of penicillin-induced focal epileptiform activity by locus coeruleus stimulation: mediation by an alpha- 1 adrenoreceptor. Epilepsia 1986; 27: 359-366.

32. Gonzales RA, Crews FT, Sumners C, et al. Norepinephrine regulation of alpha-1 receptors and alpha-1-stimulated phosphoinositide hydrolysis in primary neuronal cultures. J Pharmacol Exp Ther 1987; 242: 764-771.

33. Rosenbaum JS, Azhar S, Hoffman BB. Alpha-1 adrenergic receptor mediated polyphosphoinositide breakdown in $\mathrm{DDT}_{1}-\mathrm{MF}_{2}$ cells. Biochem Pharmacol 1987; 36: 4335-4340.

34. Nicoletti F, Iadarola MJ, Wroblewski JT, et al. Excitatory amino acid recognition sites coupled with inositol phospholipid metabolism: developmental changes and interaction with alpha-1 adrenoceptors. Proc Natl Acad Sci U.S.A. 1986; 83: 1936-1935. 